\title{
DESIGN AND ANALYSIS OF RECTRANGULAR MICRO STRIP PATCH ANTENNA USING MICROSTRIP LINE FEED METHOD AND CURVE SLOT RECTRANGULAR MICROSTIP PATCH ANTENNA USING COAXIAL PROBE FEED METHOD, AND SIMULATION BY HIGH FREQUENCY STRUCTURAL SIMULATOR
}

\author{
Shubhajit Kanti Das \\ Department of EEE
}

Swami Vivekananda Institute of Modern Science, Kolkata, WB, India

\author{
Angana Malik \\ Department of ECE \\ Techno, Kolkata, \\ WB, India
}

\begin{abstract}
With the quick development of the communication system through the world where Micro Strip Antenna is one of the imperative part of it. Here in this paper a propose model of simple micro strip patch antenna and Probe feed Rectangular Micro strip Patch Antenna (RMPA) with curve slot is presented. For designing purpose high frequency structural simulator (HFSS) is been used. Different technique are use analysis the performance of antenna. Like Curve slot technique is introduce here to evaluate bandwidth, radiation pattern, gain. And Microstrip line feed and Probe feed technique is used to provide the excitation to the simulate antenna structures. Rogers RT/Duroid material with 2.2 dielectric constant is used for substrate to design simple microstrip patch antenna. Rogers RT/Duroid material with 2.33 dielectric constant is used to design the substrate of probe feed slot patch antenna. After simulation both the antenna shows very good result on Band width, radiation pattern and returning loss.
\end{abstract}

Keywords - Micro Strips Antenna, Simple Micro Strip Patch Antenna, Probe feed Rectangular Micro strip Patch Antenna, high frequency structural simulator (HFSS), Curve slot technique, Rogers RT/Duroid material

\section{INTRODUCTION}

An antenna is a special type of transducer that converts radiofrequency $(\mathrm{RF})$ fields into alternating current (AC) or viceversa. It has a very important role in the field of wireless communication. Some of antennas are parabolic reflectors; patch antennas, slot antennas, and folded dipole antennas are used in different application field according to their properties. It is an essential part of any wireless communication such as satellites, radars, aviation, medical applications, ground penetrating radar etc, as an interface between transmitter / receiver and propagation media. But here size weight, cost, performance, ease of installation and aerodynamics profile are constraints, so low profile antennas are required. To meet these requirements, micro strip antennas can be used.

From 1970 the application of Micro strip antennas are started when conformal antennas were required for missiles. Rectangular micro strip resonant patches have been used extensively in a variety of array configurations. The major need for today's communication devices is to operate at broader band such as to support high speed internet, multimedia communication and similarly many more broadband services, this is achieved by using microstrip patch antennas, but major limitation of microstrip antennas are low gain, spurious radiation, narrow band etc. To overcome this limitation various technique are used. Micro strip antennas are often referred as patch antennas. The radiating elements and the feed lines are usually photo etched on dielectric substrate. The radiating patch may be square, rectangular, thin strip (dipole), circular, elliptical, triangular or any other configuration. Conventional microstrip patch antenna has a ground plane on the one side of a dielectric substrate and other side has a radiating patch.A rectangular patch is used in this type antenna as the main radiator. The patch is generally made of conducting material such as copper or gold and can take any possible shape. For good antenna performance, a low dielectric constant with thick dielectric substrate is desirable, as it provides better radiation, better efficiency and larger bandwidth Different types of feed methods are used in 
Microstrip patch antennas. Like as Microstrip line, coaxial probe, Aperture coupling and Proximity coupling .Microstrip line and coaxial probe line feed are two easy methods for fabrication. Co axial probe feed technique is introduce low spurious radiation. By introducing different type of slot on the rectangular patch of microstrip antenna develops the return loss, gain and radiation pattern.

In this paper two microstrip antennas of $2.3 \mathrm{GHz}$ and $3.5 \mathrm{GHz}$ is proposed. Here, microstrip rectangular patch antenna using microstrip line feeding technique is designed and analysis the result. And Coaxial probe feed microstrip patch antenna is designed and observed the result. Rogers RT/Duroid material with 2.2 dielectric constant ( $\varepsilon r$ ) is used for design substrate. Using Low dielectric constant with thick dielectric substrate, coaxial probe feed technique and curve slot in rectangular microstrip patch antenna provides numerous advantages such as low radiation leakage, good gain, large bandwidth, good radiation pattern.

\section{METHOD}

\section{A. MICRO STRIP LINE FEEDING METHOD}

Micro strip line feed is one of the easier methods to fabricate as it is a just conducting strip connecting to the patch and therefore can be consider as extension of patch. It is simple to model and easy to match by controlling the inset position. However the disadvantage of this method is that as substrate thickness increases and spurious feed radiation increases which limit the bandwidth.

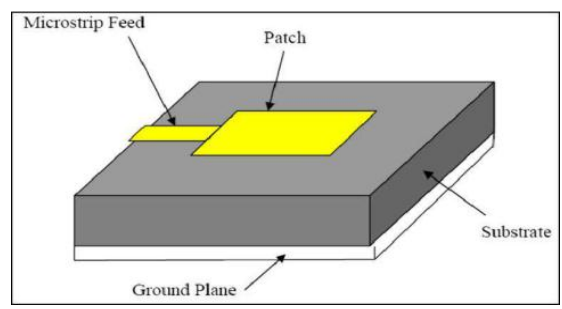

Fig. 1. Model simple rectangular micro strip patch antenna

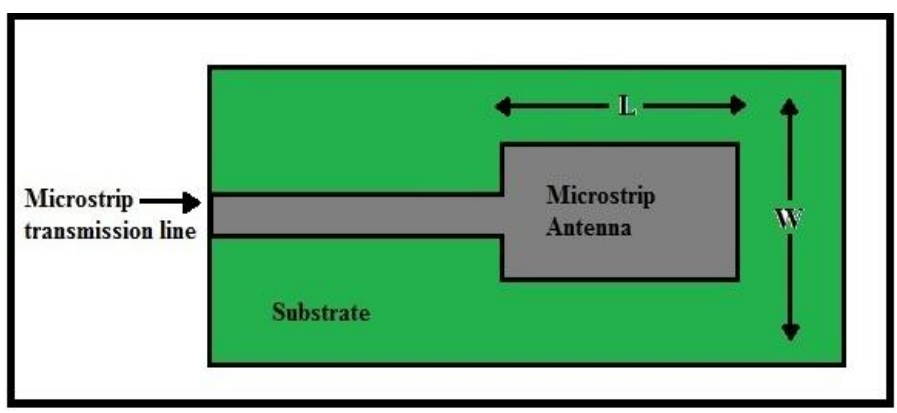

Fig. 2. Representation of Microstrip line feed

\section{B. COAXIAL CABLE OR PROBE FEEDING METHOD}

Coaxial cable and Probe feeding technique is a most popular technique and also widely used. The coaxial probe is an inner conductor that is passed through out a substrate. It is connected to an antenna to make it radiating. The coaxial probe feed technique consists of central probe conductor, which is directly connected with patch antenna, which provides its feeding power. The coax represents the outer connector around the probe. It is connected with the ground plane.

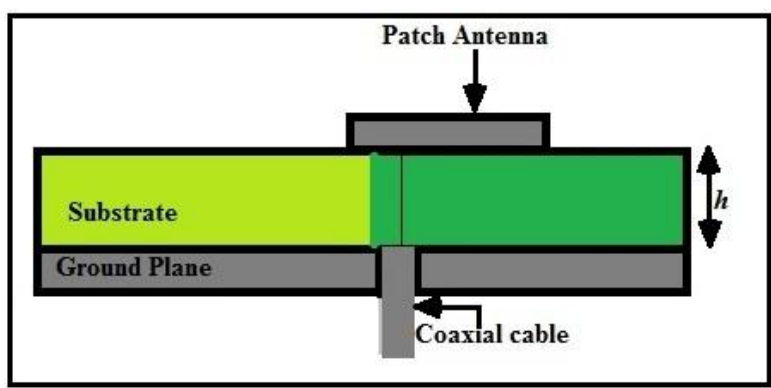

Fig. 3. Representation of coaxial or probe

. For this purpose the following formulae is use-

\section{SLOT ON PATCH}

In 1938 Alan Blumlein invented the slot antenna while working for EMI. He invented it to produce a practical type of antenna for VHF television broadcasting that would have horizontal polarization, an omnidirectional horizontal radiation pattern and a narrow vertical radiation pattern.

A slot antenna consists of a metal surface, usually a flat plate, with a hole or slot cut out. When the plate is driven as an antenna by a driving frequency, the slot radiates electromagnetic waves in a way similar to a dipole antenna. The shape and size of the slot, as well as the driving frequency, determine the radiation pattern. Slot antennas are often used at UHF and microwave frequencies instead of line antennas when greater control of the radiation pattern is needed. It also widely used in radar antennas. It is often found in standard desktop microwave sources used for research purposes. Here I designed Curve slot on rectangular patch

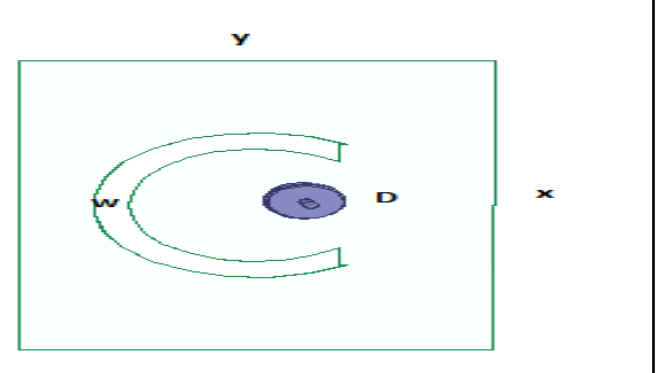




\section{International Journal of Engineering Applied Sciences and Technology, 2019 \\ Vol. 4, Issue 1, ISSN No. 2455-2143, Pages 39-44 \\ Published Online May 2019 in IJEAST (http://www.ijeast.com)}

\section{Fig. 4. curve-slot design schematic}

\section{IV.DESIGN SIMULATOR: HFSS}

- It understands the concept of antenna and analyzing the performance of antenna.

- HFSS is a high performance full wave electromagnetic field simulator for arbitrary 3D volumetric passive device .It integrates simulation visualization, solid modeling and automation is an easy to learn environment where solutions to your 3D EM problems are quickly and accurate obtained.

- ANSOFT HFSS employs the Finite Element Method (FEM), adaptive meshing and brilliant graphics to give unparalleled performance and insight to all of 3D EM problems.

- ANSOFT HFSS can be used to calculate parameters such as S-parameters, resonant frequency and felids.

\section{DESIGN AND ANALYSIS}

There are essential parameters for design of a rectangular micro strip Patch Antenna. Firstly, the resonant frequency $\left(\boldsymbol{f}_{\boldsymbol{r}}\right)$ of the antenna must be selected appropriately. In this paper, the resonant frequencies are selected for both antennas are $2.3 \mathrm{GHz}$ and $3.5 \mathrm{GHz}$. Secondly, the selection of the dielectric material for design substrate. The dielectric constant of the substrate material is an important design parameter. Low dielectric constant is used in the prototype design because it gives better efficiency and higher bandwidth, and lower quality factor Q. Another important parameter is thickness of substrate.

The antenna parameters of this antenna can be calculated by following expression

Width $(\boldsymbol{W})$ : The width of the patch is calculated using the following equation

$$
W=\frac{c}{2 f_{r}} \sqrt{\frac{2}{\varepsilon_{r}+1}}
$$

Where, $\mathrm{W}=$ Width of the patch

$\mathrm{C}=$ velocity of light $=3 \times 10^{11} \mathrm{~cm} / \mathrm{sec}$

Effective refractive index $\left(\epsilon_{r}\right)$ : The value of the effective dielectric constant $\left(\epsilon_{\mathbf{r}}\right)$ is calculated using the following equation

$$
\mathcal{E}_{\text {reff }}=\frac{\mathcal{E}_{r}+1}{2}+\frac{\mathcal{E}_{r}-1}{2}\left[1+12 \frac{h}{W}\right]^{-\frac{1}{2}}
$$

Where, $\mathrm{h}=$ height of the substrate

Length: The patch along its length now has been extended on each and by dimensions of the distance $\Delta L$. This is given as

$$
\frac{\Delta L}{h}=0.412 \frac{\left(\varepsilon_{\text {reff }}+0.03\right)\left(\frac{W}{h}+0.264\right)}{\left(\varepsilon_{\text {reff }}-0.258\right)\left(\frac{W}{h}+0.8\right)}
$$

The effective length is given by,

$$
L_{e f f}=L+2 \Delta L
$$

For a given resonating frequency $\boldsymbol{f}_{\boldsymbol{r}}$ the effective length,

$$
\begin{aligned}
& \boldsymbol{L}_{\boldsymbol{e f f}} \text { is given as, } \\
& L_{e f f}=\frac{C}{2 \times f_{r} \sqrt{\varepsilon_{\text {reff }}}}
\end{aligned}
$$

Thereby the resonant frequency is given as,

$$
f_{r}=\frac{C}{2 \times L+2 \Delta L \sqrt{\varepsilon_{\text {reff }}}}
$$

\section{DESIGN OF RECTANGULAR MICROSTRIP PATCH ANTENNA USING LINE FEED TECHNIQUE}

Rectangular patch is by far the most widely used configuration because of ease of analysis and fabrication, and their attractive radiation characteristics, especially low cross-polarization radiation. Here in this design in Fig.7 there is a ground plane (material used: rectangular sheet) over to which is a substrate layer (material used: Rogers RT/duroid $5880 \mathrm{tm}$ ), then a rectangular patch is situated over the patch.

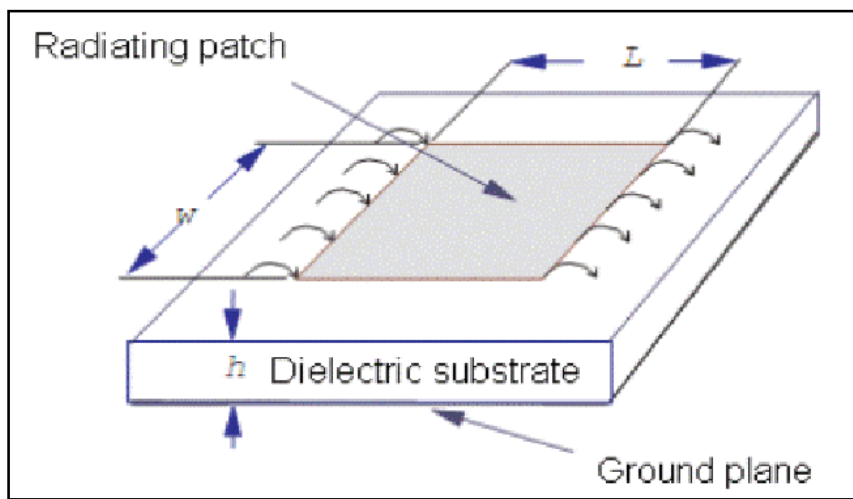

Fig. 5. Top view of Micro strip rectangular patch antenna 


\begin{tabular}{|c|c|c|}
\hline Design Elements & Material Used & $\begin{array}{c}\text { Relative } \\
\text { Permittivity }\end{array}$ \\
\hline Ground plane & Rectangular Sheet & - \\
\hline Substrate & $\begin{array}{c}\text { Rogers RT/duroid } \\
5880 \text { tm }\end{array}$ & $\mathbf{2 . 2}$ \\
\hline Radiation Box & Vaccum & $\mathbf{4 5 . 8 1 0 3}$ \\
\hline
\end{tabular}

Table 1: Representing different layers of the simple patch antenna being designed and their materials used accordingly also their respective permittivity

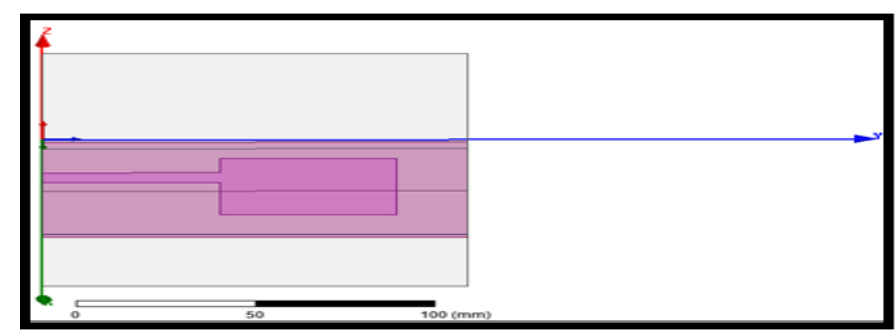

Fig. 6: Top view of micro strip antenna model with rectangular patch

\section{DESIGN OF CURVE SLOT RECTANGULAR MICROSTRIP PATCH ANTENNA USING PROBE FEED TECHNIQUE}

Though simple or conventional rectangular micro strip patch antenna is widely used, but it has some disadvantages. To overcome those problem we are studying about probe feed rectangular patch antenna model. In this section the designing of probe feed rectangular patch antenna with slot is discussed. Here in this design in Fig. $8 \& 9$ there is a ground plane (material used: copper) over to which is a substrate layer (material used: Rogers RT/duroid $5880 \mathrm{tm}$ ), then a rectangular patch is situated over the patch. Here coaxial cable or probe feed is used. The outer conductor of the coaxial cable is connected to the ground plane, and the centre conductor is extended up to the patch antenna. The position of the feed can be altered to control the input impedance.

\begin{tabular}{|c|c|c|}
\hline Design Elements & Material Used & $\begin{array}{c}\text { Relative } \\
\text { Permittivity }\end{array}$ \\
\hline $\begin{array}{c}\text { Ground plane, } \\
\text { probe }\end{array}$ & Copper & 1 \\
\hline Substrate & $\begin{array}{c}\text { Rogers RT/duroid } \\
5870 \text { tm }\end{array}$ & 2.33 \\
\hline Radiation Box & Vacuum & 1 \\
\hline
\end{tabular}

Table 2: Representing different layers of the simple patch antenna being designed and their materials used accordingly also their respective permittivity

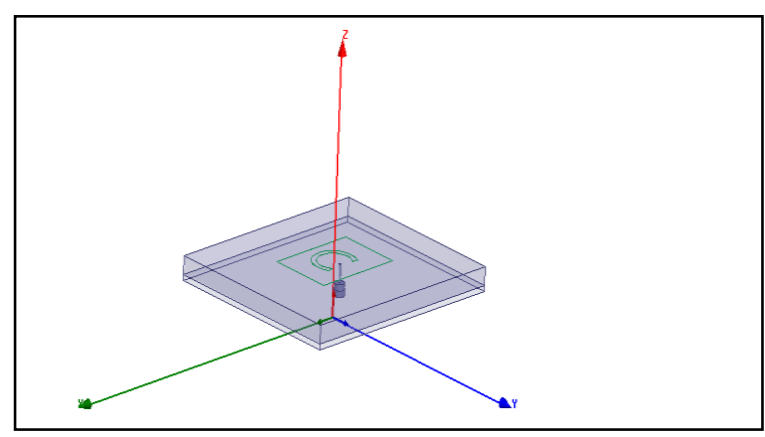

Fig. 7: 3D view of probe feed micro strip rectangular patch slot antenna

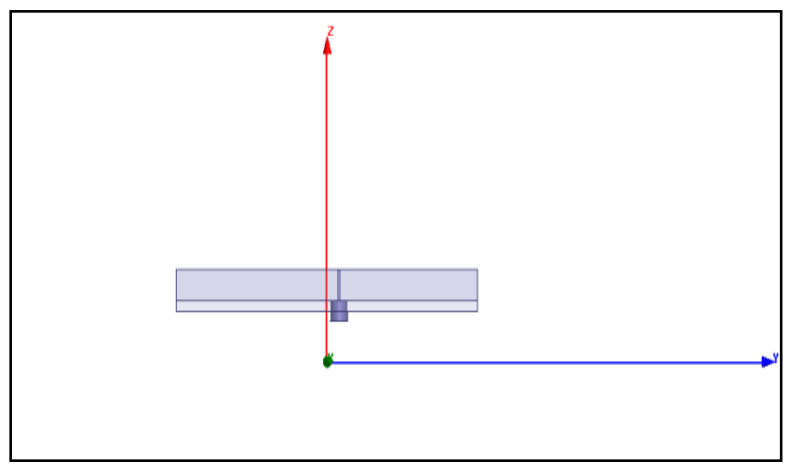

Fig. 8: side view of probe feed micro strip rectangular patch slot antenna

\section{FEED LOCATION DESIGN}

The feeding probe point location can be located at the point $\left(X_{f}, Y_{f}\right)$ in the $\mathrm{x}-\mathrm{y}$ coordinates, as shown in Figure-10. The location points are given by following equation. They had achieved low input impedance or good matches between the transmission line and the port. The position of the coaxial cable can be obtained by using,

$$
\begin{gathered}
x_{f}=\frac{l}{\sqrt[2]{\varepsilon_{\text {reff }}}} \\
y_{f}=\frac{w}{2}
\end{gathered}
$$

Where $x_{f}$ and $y_{f}$ the desire is input impedance to match the coaxial cable and $\varepsilon_{\text {reff }}$ is the effective dielectric constant. 


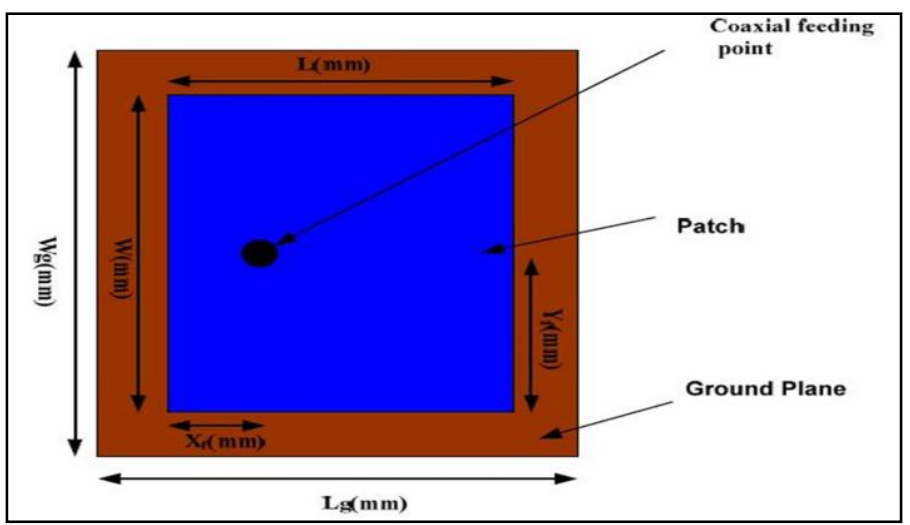

Fig. 9: A schematic diagram of patch antenna with feed points of coaxial probe

\section{CURVE SLOT DESIGN}

In this section curve slot is designed on the rectangular patch. For design the curve on patch we assume the value of slot distance (D), width (W), and position (C) etc.

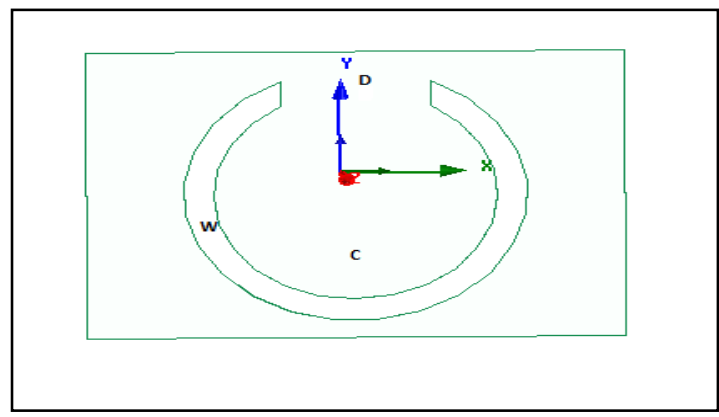

Fig.10: Dimension of curve- slot design

\begin{tabular}{|c|c|c|}
\hline $\mathrm{W}$ & $\mathrm{D}$ & $\mathrm{C}$ \\
\hline $2 \mathrm{~mm}$ & $10 \mathrm{~mm}$ & $16 \mathrm{~mm}$ \\
& & \\
\hline
\end{tabular}

Table 3 Dimension of curve-slot patch antenna

\section{SIMULATIONS AND RESULTS}

Here HFSS simulation software is used for simulating both antennas. The simulated result of return loss and radiation pattern of micro strip patch antenna and probe feed micro strip patch antenna with curve slot shown in bellow figures.

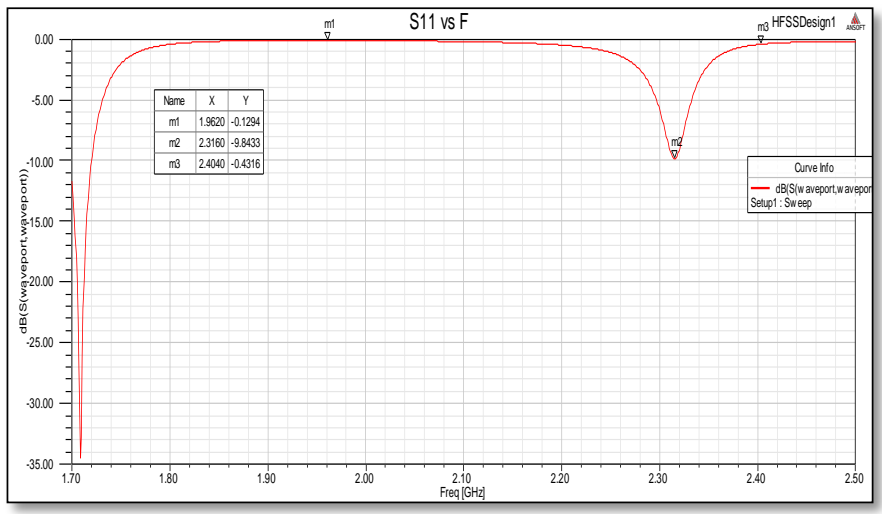

Fig.11: Plot of reflection coefficient ( $\left.S_{11}\right)$ vs. frequency for rectangular patch micro strip antenna, $S_{11}(\mathrm{~dB})$ on yaxis, frequency $(\mathrm{GHz})$ on $x$ axis at frequency $2.3 \mathrm{GHz}$

Return loss is used to indicate the amount of power that is lost to load, and the lost power does not return as reflection. The value of return loss of microstrip rectangular patch antenna is $9.84 \mathrm{~dB}$ at the center frequency $2.3 \mathrm{GHz}$. The bandwidth obtained from the fig. is $19.04 \%$.The value of return loss of probe feed microstrip patch antenna is $-34.09 \mathrm{~dB}$ at center frequency $3.43 \mathrm{MHz}$.Bandwidth is $23.8 \%$.

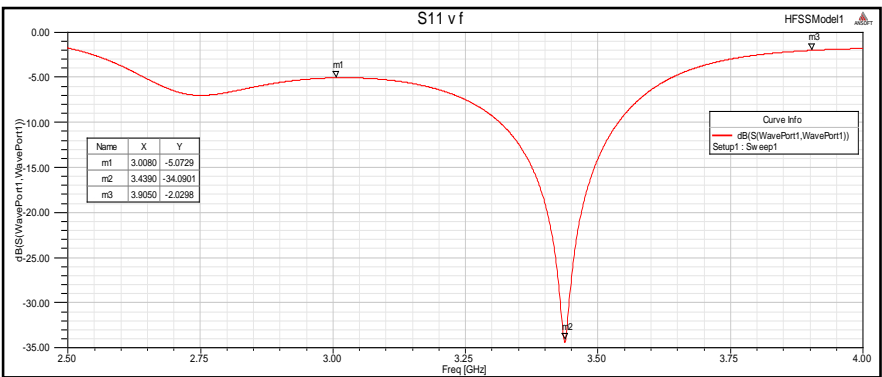

Fig. 12: Plot of reflection coefficient ( $\left.S_{11}\right)$ vs. frequency for probe feed curve slot rectangular patch micro strip antenna, $S_{11}(\mathrm{~dB})$ on y-axis, frequency $(\mathrm{GHz})$ on $\mathrm{x}$ axis at frequency $3.5 \mathrm{GHz}$ 


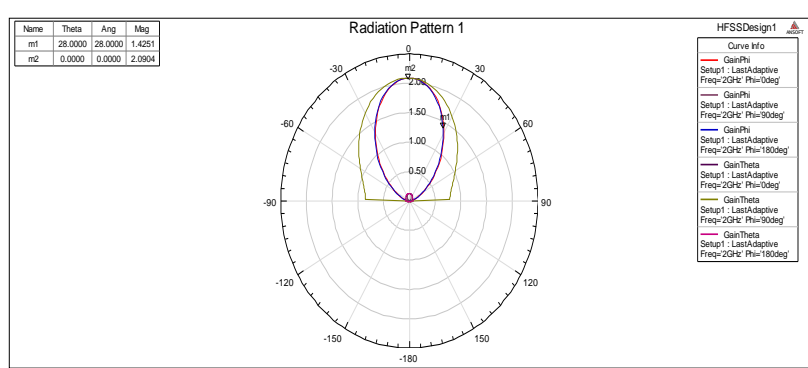

Fig. 13: Radiation pattern for micro strip rectangular patch antenna showing gain phi and gain theta both for 0deg \& 90deg at frequency $2.3 \mathrm{GHz}$

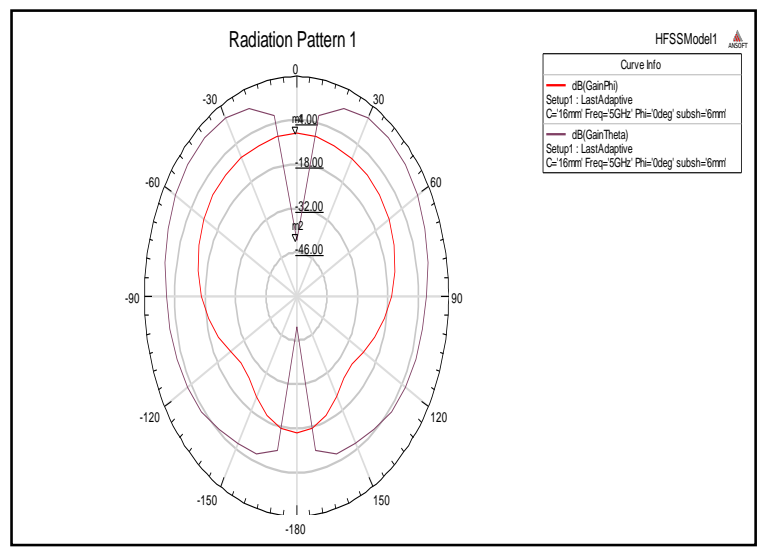

Fig.

14: Radiation pattern for probe feed curve slot microstrip rectangular patch antenna showing gain phi and gain theta both for 0deg \& 90deg at frequency $3.4 \mathrm{GHz}$

\begin{tabular}{|c|c|c|c|}
\hline Antenna type & $\begin{array}{c}\text { Simulated } \\
\text { frequency }\end{array}$ & $\begin{array}{c}\text { Calculated } \\
\text { Resonant } \\
\text { Frequency }\end{array}$ & \\
\hline $\begin{array}{c}\text { Simple Micro strip } \\
\text { rectangular patch } \\
\text { antenna }\end{array}$ & $2.3 \mathrm{GHz}$ & $2.2 \mathrm{GHz}$ & \\
\hline $\begin{array}{c}\text { Probe Feed Slot } \\
\text { Micro strip Patch } \\
\text { Antenna }\end{array}$ & $3.4 \mathrm{GHz}$ & $3.5 \mathrm{GHz}$ & \\
\hline
\end{tabular}

Table 4: Representing theoretical and simulated resonant frequency for simple and inverted patch antenna.

\section{CONCLUSION}

After going through details analysis, simulation and result shown in the paper, a conclusion can be drawn that the design of the rectangular micro strip patch antenna using line feed antenna produce a bandwidth of $19.4 \%$ and curve slot rectangular micro strip antenna using probe feed technique produced a bandwidth of $23.8 \%$ with stable radiation pattern.
The value of return loss of the antenna at frequency $2.3 \mathrm{GHz}$ are $-9.84 \mathrm{~dB}$ and -34.09 respectively, all the data shown in table 5. Return loss is used to indicate the amount of power that is lost to load, and the lost power does not return as reflection. As the returning loss is within the appropriate range we can use this antenna. From the data tabulated in table 4 , it can be state that the result is satisfactory because simulated frequency and Calculated Resonant Frequency is almost equal.

\section{REFERENCE}

[1] Balanis, C.A.(2005), “Antenna Theory Analysis and Design”, Textbook 3rd Edition,(page 811-835).

[2] Murthi Mahadeva Naik G., Kumar Naveen S.K., Bhavya B.P,(2015), Performance analysis of micro strip patch antenna using coaxial probe Feed technique,(pp 365-367)

[3] Karthikeyan V and Vijayalakshmi V.J.,( 2014), Radiation Pattern of Patch antenna with slits. International Journal on information Theory (DOI: $10.5121 /$ ijit.2014.3101.1)

[4] E. H. Newman, D. Rorrai,(1987) Scattering from a Microstip Patch,(pp.245-251)

[5] Hrucha R. Kharat, Madhuri D. Khetmalis, Shruti H. Pimpalgaonkar and Prof. Rameez Shamalik, (2016), Design And Analysis Of Compact U Slot MicrostripPatch Antenna For Wireless Applications, (pp. 7-14).

[6] W. W. Xu, J. H. Wang, Z. Zhang, and M. E. Chen,(2011) International Symposium on Microwave, Antenna, Propagation and EMC Technologies for Wireless Communications,(pp. 124127).

[7] H. Cheng Chi,(2000), "An aperture-coupled linear microstrip leaky-wave antenna array with twodimensional dual-beam scanning capability,( pp. 909. 913).

[8] K. Gi-Cho,(2014), Ku-band high efficiency antenna with corporate series-fed microstrip array,(pp. 690 693).

[9] Kharat Hrucha R., Khetmalis Madhuri D Pimpalgaonkar Shruti $\mathrm{H}$ and Shamalik Rameez,(2016), Design And Ahalysis Of Compact U Slot MicrostripPatch Antenna For Wireless Applications,(pp. 7-14).

[10] Gupta P, (2013), Evolvement of mobile generations: $1 \mathrm{G}$ to $5 \mathrm{G},(\mathrm{pp} 152-157)$.

[11] Rappaport T.S., Gutierrez F., E. Ben-Dor, Murdock J.N., Qiao Yijun, Tamir,(2013), Broadband millimeter-wave propagation measurements andmodels using adaptive-beam antennas for outdoor urban cellular communications,(pp 1850-1859).

[12] Murugan S., Sathish kumar E., and Rajamani V.,(2013.)Design and Analysis of Double U Slot Loaded 